\title{
Sex-Differences of Low to Moderate Leisure-Time Physical Activity on Metabolic Risk Factors in Type 2 Diabetes Mellitus Patients
}

\author{
Yu Hui-I* \\ Division of Endocrinology and Metabolism, Department of Internal Medicine, Chia-Yi Christian Hospital, Taiwan \\ Department of Sports Management, Chia Nan University of Pharmacy and Science, Taiwan
}

Received: January 05, 2015; Accepted: March 31, 2015; Published: April 13, 2015

*Corresponding author: Yu Hui-I, Division of Endocrinology and Metabolism, Department of Internal Medicine, Chia-Yi Christian Hospital, Taiwan, Tel: 88652765041; E-mail: cych04490@gmail.com

\begin{abstract}
Background: Exercise is an integral part of the diabetes management and prevention. However, it is hard to maintain and to reach current recommendation due to the unavoidable aging process. This cross-sectional study investigates our type 2 diabetes patients participating in our DM education program from January to December 2011 to find out if low to moderate physical activity could have benefits and to investigate if there were sex- differences of benefits.

Results: In 3240 type 2 DM patients, 53.7\% had Leisure Time Physical Activity (LTPA) but only $24.7 \%$ had adequate LTPA. Those who had adequate physical activity had lower BMI, longer DM duration ( $10.4 \pm 7.6$ vs $8.4 \pm 6.8$ years). Significantly less smoking, betel-nut chewing and alcohol drinking habits in male adequate LTPA group was found. The benefits of exercise in male subjects includes lower hemoglobulin A1C $(7.4 \pm 1.4$ vs $7.9 \pm 1.8 \%)$, lower diastolic blood pressure $(80.0 \pm 11.6$ vs $82.9 \pm 12.2 \mathrm{mmHg})$, triglyceride (136.8 \pm 89.0 vs $152.3 \pm 114.0)$, GPT ( $34.8 \pm 29.0$ vs $39.8 \pm 37.3$ ), Creatinine $(1.20 \pm 0.45$ vs $1.28 \pm 0.94)$. The benefit of exercise in female is lower GPT only $(30.6 \pm 27.5$ vs $34.4 \pm 31.2)$. The difference might be a result of less exercise intensity and volume in female subjects. The mean METs are $3.4 \pm 1.1$ in male and $3.1 \pm 1.0$ in female, $P=0.000$, MET min/ week are $1303.7 \pm 792.4$ (38.5) in male group, $1188.6 \pm 757.7$ (39.01) in female group respectively, $p=0.036$. Correlation analysis showed exercise volume is the determinant of better glycemic control.
\end{abstract}

Conclusion: Adequate low to moderate LTPA appears to help the achievement of metabolic risks reduction in male subjects only, who also demonstrated a healthier lifestyle. Exercise intensity and volume were higher in male subjects too. To enhance metabolic benefits from low intensity LTPA, increase of exercise volume is probably needed.

Keywords: Physical Activity ; Type 2 Diabetes Mellitus ; Patients ; Sex-Differences

\section{Introduction}

The incidence of type 2 diabetes mellitus is increasing dramatically all over the world. Though there is a genetic predisposition, its occurrence is linked to obesity and inactivity $[1,2]$. Exercise is an important part of the diabetes management plan and prevention of diabetes mellitus [3,4]. Regular exercise has been shown to improve blood glucose control, reduce inflammation, reduce cardiovascular risk factors, and improve quality of life etc $[3,5]$. The US department of Health and Human services' physical activity guidelines for Americans recommends that adults over age 18 years perform 150 min per week of moderate-intensity or $75 \mathrm{~min}$ per week of vigorous aerobic physical activity or an equivalent combination of the two [6]. However studies showed physical activity levels are often low in the elderly [7] especially in type 2 diabetic patients. In diabetes Prevention Program, weight loss $>3 \%$ through exercise and diet control yielded greater reduction in risk factors for diabetes in men than in women [8]. Another study showed resistance training lowers diastolic blood pressure to a greater extent in women [9]. In this cross-sectional study we investigate the metabolic benefits of physical activity in real world and to see if there are sex differences of benefits.

\section{Methods}

Data were compiled from our diabetes education program in Chia-Yi Christian Hospital in Taiwan. 3451 diabetic patients who completed at least one year of follow up from Jan 2011 to the end of 2011 were included in this survey. 69 patients with type 1 diabetes mellitus were excluded. Twelve patients with type 2 diabetes mellitus who were less than 18 years of age were excluded. 130 patients with incomplete data were excluded, too. Finally, 3240 type 2 diabetic patients were included. All patients have annual data collection after they entered the education program.

Assessment of Leisure Time Physical Activity (LTPA): LTPA was assessed initially and then once every year after they entered education program. They were asked about the type of physical activities that they were involved most during the prior three months, e.g. walking, jogging, cycling, swimming, dancing and other exercise. They were also asked the average frequency (times/week) and duration of activity each time (min/ 
time). For example a patient would say that the activity she did most often was walking and she had walked 30 min each time, 5 times weekly. We also asked her about the intensity of selfperceived exertion and the distance she walked in 30 minutes. Then according to 2011 Compendium, we can find the estimate exercise intensity, expressed in METs (metabolic equivalents). Then we summed the activities with weekly time to yield a MET-min/week score. One MET is the energy expended by sitting quietly which is equivalent to $3.5 \mathrm{ml} / \mathrm{min} / \mathrm{kg}$ of oxygen consumption. Though the American College of Sports Medicine and American Diabetes Association suggests that individuals obtain 75 minutes of vigorous aerobic exercise per week, or 150 minutes of moderate aerobic exercise per week are adequate. So, their weekly physical activities reaching 600 MET-min per week were defined as adequate physical activity. Those who did not have LTPA were defined as sedentary group; those who had LTPA but did not reach 600 MET-min/week threshold comprised the inadequate physical activity group. The 2011 Compendium of physical activity provides uptake MET values as references. (http://sites.google.com/site/compendiumofphysicalactivities)

Clinical data including smoking, alcohol drinking habits were collected by diabetic educators at baseline and then yearly. Stroke was defined as any past ischemic stroke or hemorrhagic stroke admission or image study indicating old stroke like lacunar infarction. Coronary artery disease was defined as any past admission for unstable angina, acute coronary syndrome or angiography result compatible with coronary artery disease or history of angioplasty or bypass surgery.

Measurements of anthropometrics, foot examination were done by trained educators. Venous blood samples were collected after 12 hour overnight fasting. The data collection was approved by Ditmanson Medical Foundation, Chia Yi Christian hospital IRB 201016.

\section{Statistics and data analysis}

The clinical and biochemical features of the patients were described as mean \pm SD (SEM) or percentages. A one-way Analysis of Variance (ANOVA) was used to compare baseline characteristics between three groups of continuous variables. Bonferroni correction was applied to locate differences between LTPA groups. A chi-squared test $\left(\chi^{2}\right)$ was used to compare baseline characteristics between categorical variables. To investigate the correlation with exercise volume and exercise intensity with metabolic risk factors, Pearson's correlation test was used. Statistical comparisons were considered significant when $p$ value were $<0.05$. All statistical analyses were performed using the SPSS statistical package, version 19.0 (SPSS, Chicago, IL).

\section{Results}

$53.7 \%$ of type 2 diabetic patients were considered to have LTPA. However, only about half $(24.7 \%)$ of them had adequate amount of LTPA. Table 1 summarizes the basic characteristics of type 2 diabetic patients in different PA groups. Those who had LTPA had lower BMI but longer diabetes duration and were older. In males with adequate LTPA, they were less likely to smoke, chew betel-nut and drink alcohol. And they were more likely to perform Self-Monitoring of Blood Glucose (SMBG). There were no differences of stroke and Coronary Artery Disease (CAD) among different PA groups.

Table 2 showed overall and sex differences of metabolic parameters among different LTPA groups. In general, those with adequate LTPA had better metabolic indexes like lower hemoglobin A1C level, lower diastolic blood pressure, lower triglyceride level, lower GPT and higher HDL level. In male subjects, the difference is more prominent than in female subjects. In female subjects, adequate LTPA demonstrated liver profile decrease only.

We used 2011 Compendium of physical activities codes to evaluate intensity of physical activities. In lower LTPA group, their mean METs are $2.8 \pm 0.7$ in male group and $2.6 \pm 0.4$ in female group, $P=0.000$. Their MET min/week did not show significant difference (male: $359.8 \pm 150.5$, female: $375.6 \pm$ 156.7). In adequate LTPA group, mean METs are $3.4 \pm 1.1$ in male and $3.1 \pm 1.0$ in female, $P=0.000$, MET $\mathrm{min} /$ week are $1303.7 \pm$ 792.4 (38.5) in male group, $1188.6 \pm 757.7$ (39.01) in female group respectively, $P=0.036$.

Table 3 showed he medication used among different PA groups. The glycemic treatment regimen including insulin therapy didn't show significant difference between groups. However antihypertensive agents were used more frequently in LTPA groups and fibrate drugs were used less frequently in LTPA groups.

Table 4 demonstrated the correlation between exercise volume and intensity versus metabolic risk factors in type 2 diabetes. It showed that exercise volume presented by MET min/ week correlated with $\mathrm{A} 1 \mathrm{C}$ reduction, diastolic blood pressure lowering and triglyceride, creatinine decreased significantly. Exercise intensity presented by MET of each exercise did not correlate with glycemic control. This correlation was more prominent in male subjects.

\section{Discussion}

The results of our study demonstrate metabolic benefits of adequate LTPA in type 2 diabetic patients. They have significantly better glycemic and diastolic blood pressure control, lowered levels of triglyceride and GPT and higher levels of HDL-C. The beneficial effects seemed more prominent in male diabetic patients, as compared to female diabetes. In our study the improved glycemic control was seen only in male diabetic patients. Though several intervention studies of small number and variable duration in the past showed that exercise of more than light to moderate intensity may be effective in improving glycemic control $[10,11]$, they did not investigate sex differences. In Boul's meta-analysis [10], exercise intensity is positively correlated with glycemic control but exercise volume was not. Another systemic review with meta-regression analysis showed supervised aerobic exercise volume is associated with A1c reduction while exercise intensity is not [12]. In IDES study, 
Table 1: Basic Characteristics for Type 2 DM in Different PA Groups.

\begin{tabular}{|c|c|c|c|c|}
\hline $\begin{array}{c}\text { Mean } \pm \text { SD } \\
(\text { SEM) }\end{array}$ & $\begin{array}{c}\text { adequate LTPA }(n=800) \\
\text { M/F } \\
(n=423 / 377)\end{array}$ & $\begin{array}{c}\text { low LTPA } \\
(n=941) \\
M / F(n=404 / 537)\end{array}$ & $\begin{array}{c}\begin{array}{c}\text { sedentary } \\
(n=1499)\end{array} \\
M / F(n=755 / 744)\end{array}$ & $P$ value \\
\hline Age $(y / o)$ & $62.0 \pm 11.1^{\mathrm{a}}(0.293)$ & $61.4 \pm 11.0^{\mathrm{b}}(0.360)$ & $\begin{array}{c}57.6 \pm 12.1 \\
(0.313)\end{array}$ & 0.000 \\
\hline $\operatorname{Sex}(M, \%)$ & 52.9 & 42.9 & 50.4 & 0.190 \\
\hline BMI $\left(\mathrm{kg} / \mathrm{m}^{2}\right)$ & $25.0 \pm 3.6^{\mathrm{a}}$ & $25.5 \pm 4.0^{b}$ & $26.2 \pm 4.3$ & 0.000 \\
\hline DM duration (years) & $10.4 \pm 7.6^{\mathrm{a}}(0.0267)$ & $\begin{array}{c}9.8 \pm 6.9^{b} \\
(0.225)\end{array}$ & $\begin{array}{c}8.4 \pm 6.8 \\
(0.175)\end{array}$ & 0.000 \\
\hline $\begin{array}{c}\text { Current } \\
\text { Smoker (\%) }\end{array}$ & & & 21.3 & 0.000 \\
\hline $\begin{array}{c}\text { Male } \\
\text { Female }\end{array}$ & $\begin{array}{c}26.2 \\
1.3\end{array}$ & $\begin{array}{c}26.2 \\
0.7\end{array}$ & $\begin{array}{c}40.0 \\
2.5\end{array}$ & $\begin{array}{l}0.000 \\
0.057\end{array}$ \\
\hline $\begin{array}{l}\text { Betel nut }(\%) \\
\text { Male } \\
\text { Female }\end{array}$ & $\begin{array}{l}2.4 \\
4.3 \\
0.3\end{array}$ & $\begin{array}{l}3.5 \\
7.9 \\
0.2\end{array}$ & $\begin{array}{c}7.5 \\
14.6 \\
0.3\end{array}$ & $\begin{array}{l}0.000 \\
0.000 \\
0.951\end{array}$ \\
\hline $\begin{array}{c}\text { Alcohol drinking }(\%) \\
\text { Male } \\
\text { Female }\end{array}$ & $\begin{array}{c}7.0^{\mathrm{a}} \\
12.8 \\
0.5\end{array}$ & $\begin{array}{l}4.7 \\
9.9 \\
0.7\end{array}$ & $\begin{array}{c}11.1 \\
20.3 \\
1.9\end{array}$ & $\begin{array}{l}0.000 \\
0.000 \\
0.072\end{array}$ \\
\hline $\begin{array}{l}\text { SMBG (\%) } \\
\text { Male } \\
\text { Female }\end{array}$ & $\begin{array}{l}51.1 \\
54.4 \\
47.5\end{array}$ & $\begin{array}{l}47.2 \\
50.5 \\
44.7\end{array}$ & $\begin{array}{l}42.0 \\
42.8 \\
41.3\end{array}$ & $\begin{array}{l}0.000 \\
0.000 \\
0.123\end{array}$ \\
\hline Stroke Hx (\%) & $4.7 / 1.9$ & $4.5 / 4.1$ & $3.4 / 4.4$ & $0.5 / 0.086$ \\
\hline CAD Hx (\%) & $8.3 / 3.4$ & $6.4 / 5$ & $5 / 4.2$ & $0.087 / 0.498$ \\
\hline
\end{tabular}

$\mathrm{a}=>150 \mathrm{~min}$ PA vs no PA, $\mathrm{p}<0.05$,

$\mathrm{b}=>150 \mathrm{~min}$ PA vs $<150$ min PA $\mathrm{p}<0.05$

Table 2: Metabolic Parameters in Different PA Groups

\begin{tabular}{|c|c|c|c|c|}
\hline $\begin{array}{c}\text { Mean } \pm \text { SD } \\
\text { (SEM) } \\
\text { M/F number }\end{array}$ & $\begin{array}{l}\text { Adequate LTPA } \\
\qquad \begin{array}{c}N=800 \\
(408 / 360)\end{array}\end{array}$ & $\begin{array}{c}\text { Less LTPA } \\
N=941 \\
(422 / 561)\end{array}$ & $\begin{array}{c}\text { sedentary } \\
N=1499 \\
(822 / 795)\end{array}$ & $P$ value \\
\hline $\begin{array}{c}\text { AC }(\mathrm{mg} / \mathrm{dl}) \\
\text { Male } \\
\text { Female }\end{array}$ & $\begin{array}{c}136.8 \pm 43.8 \\
(1.549) \\
136.8 \pm 43.9 \\
136.8 \pm 43.8\end{array}$ & $\begin{array}{c}138.5 \pm 47.9 \\
(1.562) \\
139.8 \pm 49.4 \\
137.5 \pm 46.7\end{array}$ & $\begin{array}{c}140.9 \pm 50.3 \\
(1.3) \\
143.4 \pm 53.2 \\
138.4 \pm 47.2\end{array}$ & $\begin{array}{l}0.13 \\
0.088 \\
0.849\end{array}$ \\
\hline $\begin{array}{c}\text { A1C (\%) } \\
\text { Male } \\
\text { Female }\end{array}$ & $\begin{array}{c}7.5 \pm 1.4^{\mathrm{a}, \mathrm{c}} \\
(0.048) \\
7.4 \pm 1.4^{\mathrm{a}} \\
7.6 \pm 1.4\end{array}$ & $\begin{array}{l}7.6 \pm 1.6^{b} \\
(0.0508) \\
7.7 \pm 1.7 \\
7.7 \pm 1.4\end{array}$ & $\begin{array}{c}7.8 \pm 1.7 \\
(0.044) \\
7.9 \pm 1.8 \\
7.8 \pm 1.6\end{array}$ & $\begin{array}{l}0.000 \\
0.000 \\
0.087\end{array}$ \\
\hline $\begin{array}{c}\text { sBP (mmHg) } \\
\text { Male } \\
\text { Female }\end{array}$ & $\begin{array}{c}137.3 \pm 18.0 \\
(0.636) \\
136.5 \pm 18.1 \\
138.1 \pm 17.9\end{array}$ & $\begin{array}{c}138.1 \pm 18.8 \\
(0.363) \\
135.4 \pm 18.3 \\
140.1 \pm 19.0\end{array}$ & $\begin{array}{c}137.7 \pm 19.3 \\
(0.499) \\
136.7 \pm 18.5 \\
138.6 \pm 20.1\end{array}$ & $\begin{array}{l}0.652 \\
0.465 \\
0.220\end{array}$ \\
\hline $\begin{array}{c}\mathrm{dBP}(\mathrm{mmHg}) \\
\text { Male } \\
\text { Female }\end{array}$ & $\begin{array}{c}80.0 \pm 11.5^{\mathrm{a}} \\
(0.406) \\
80.0 \pm 11.6^{\mathrm{a}} \\
80.1 \pm 11.4\end{array}$ & $\begin{array}{c}80.8 \pm 11.1^{\mathrm{b}} \\
(0.363) \\
80.0 \pm 11.6^{\mathrm{b}} \\
81.3 \pm 10.8\end{array}$ & $\begin{array}{c}83.0 \pm 27.2 \\
(0.702) \\
82.9 \pm 12.2 \\
83.1 \pm 36.6\end{array}$ & $\begin{array}{l}0.001 \\
0.008 \\
0.158\end{array}$ \\
\hline $\begin{array}{c}\text { T.C }(\mathrm{mg} / \mathrm{dl}) \\
\text { Male } \\
\text { Female }\end{array}$ & $\begin{array}{c}179.1 \pm 34.3 \\
(1.214) \\
177.6 \pm 34.7 \\
180.7 \pm 33.9\end{array}$ & $\begin{array}{c}178.1 \pm 35.1 \\
(1.44) \\
173.0 \pm 34.1 \\
181.9 \pm 35.4\end{array}$ & $\begin{array}{c}179.9 \pm 33.6 \\
(0.972) \\
177.5 \pm 38.7 \\
182.4 \pm 36.4\end{array}$ & $\begin{array}{l}0.473 \\
0.101 \\
0.738\end{array}$ \\
\hline $\begin{array}{c}\text { TG }(\mathrm{mg} / \mathrm{dl}) \\
\text { Male } \\
\text { Female }\end{array}$ & $\begin{array}{c}133.5 \pm 96.1^{\mathrm{a}, \mathrm{c}} \\
(3.396) \\
136.8 \pm 89.0^{\mathrm{a}} \\
129.9 \pm 103.4\end{array}$ & $\begin{array}{c}135.5 \pm 84.2^{b} \\
(2.744) \\
136.4 \pm 80.6^{b} \\
134.9 \pm 86.9\end{array}$ & $\begin{array}{c}147.2 \pm 104.3 \\
(2.694) \\
152.3 \pm 114.0 \\
142.0 \pm 93.2\end{array}$ & $\begin{array}{l}0.001 \\
0.008 \\
0.104\end{array}$ \\
\hline
\end{tabular}

Citation: Hui-I Y (2015) Sex-Differences of Low to Moderate Leisure-Time Physical Activity on Metabolic Risk Factors in Type 2 Diabetes Mellitus Patients. J Endocrinol Diab 2(2): 5. DOI: http://dx.doi.org/10.15226/2374-6890/2/2/00118 


\begin{tabular}{|c|c|c|c|c|}
\hline HDL-C (mg/dl) & $54.2 \pm 14.7^{\mathrm{a}}$ & $53.4 \pm 14.5$ & $52.6 \pm 14.0$ & $(0.362)$ \\
Male & $(0.521)$ & $(0.473)$ & $49.2 \pm 13.2$ & 0.037 \\
Female & $50.8 \pm 13.2$ & $48.8 \pm 13.3$ & $56.1 \pm 14.0$ & 0.060 \\
\hline LDL-C (mg/dl) & $58.1 \pm 15.4^{\mathrm{a}, \mathrm{b}}$ & $56.8 \pm 14.4$ & $105.8 \pm 31.7$ & 0.090 \\
Male & $105.8 \pm 31.0$ & $105.1 \pm 30.7$ & $0.820)$ & 0.838 \\
Female & $(1.095)$ & $(1.001)$ & $105.6 \pm 31.5$ & 0.512 \\
\hline GPT (mg/dl) & $106.4 \pm 31.2$ & $103.9 \pm 31.8$ & $106.1 \pm 32.0$ & 0.902 \\
\hline Male & $105.2 \pm 30.7$ & $106.0 \pm 29.9$ & $37.1 \pm 34.5$ & 0.001 \\
Female & $32.6 \pm 27.8^{\mathrm{a}}$ & $33.5 \pm 30.0^{\mathrm{b}}$ & $(0.891)$ & 0.046 \\
\hline
\end{tabular}

$\mathrm{a}=>150 \mathrm{~min} \mathrm{PA}$ vs no $\mathrm{PA}, \mathrm{p}<0.05, \mathrm{~b}=<150 \mathrm{~min} \mathrm{PA}$ vs no $\mathrm{PA}, \mathrm{p}<0.05$

$\mathrm{c}=>150 \mathrm{~min}$ PA vs $<150 \mathrm{~min}, \mathrm{PA} \mathrm{P}<0.05$

Table 3: Medication history between PA groups.

\begin{tabular}{|c|c|c|c|c|}
\hline & $\begin{array}{l}\text { Adequate LTPA } \\
\qquad(\mathrm{N}=\mathbf{8 0 0})\end{array}$ & $\begin{array}{c}\text { Less LTPA } \\
(N=941)\end{array}$ & Sedentary $(N=\quad 1499)$ & $P$ value \\
\hline OAD (\%) & 97.5 & 96.5 & 96.7 & 0.543 \\
\hline Insulin (\%) & 20.2 & 23 & 25.8 & 0.058 \\
\hline Antihypertensive agent (\%) & 58.1 & 57.8 & 48.3 & 0.002 \\
\hline Statin $(\%)$ & 35 & 34.1 & 33.7 & 0.819 \\
\hline Fibrate $(\%)$ & 9 & 9.4 & 11.9 & 0.044 \\
\hline Antiplatelet (\%) & 12 & 10.4 & 9.5 & 0.166 \\
\hline
\end{tabular}

Table 4: Pearson correlation of exercise volume and exercise intensity to metabolic risk factors.

\begin{tabular}{|l|l|l|l|l|l|l|l|}
\hline & $\begin{array}{l}\text { Exercise } \\
\text { volume }\end{array}$ & $\begin{array}{l}\text { Exercise } \\
\text { intensity }\end{array}$ & A1C & dBP & TG & HDL-C \\
\hline Exercise volume & 1 & 0.379 & $-0.065^{*}$ & $-0.053^{*}$ & $-0.055^{*}$ & 0.024 & -0.023 \\
\hline Exercise intensity & 0.379 & 1 & -0.017 & 0.031 & -0.032 & $-0.057^{*}$ \\
\hline
\end{tabular}

${ }^{*} P<0.05$

adequate exercise volume improved metabolic control even with low intensity exercise [13]. In our study, male patients had significantly higher exercise intensity and exercise volume, which is expected. A correlation analysis showed that exercise volume is negatively association with $\mathrm{A} 1 \mathrm{C}$ more significantly than exercise intensity, which result is compatible with previous studies. In female subjects, if exercise volume is extrapolated to be over 800 METmin/week, significant A1C reduction is expected.

Adequate physical activity group also had lower BMI and waist circumference, which is consistent with the results of previous studies [14], except one previous meta-analysis [10] that did not show structured exercise, had significant BMI impact.

Lower TG and higher HDL-C were seen more frequently in adequate exercise group especially in male. This might be explained by the following reasons. First, exercise improves insulin sensitivity [6], which is instrumental in ameliorating the unfavorable lipid profiles. Second, the adequate physical activity group at baseline might have lower waist level and BMI, which were known to be associated with lower TG level and HDL-C elevation. Third, in male diabetes the prevalence of smoking and alcohol drinking were significantly lower, which were expected to contribute to HDL-C elevation and TG lowering. Patients in adequate physical activity group also have significantly lower GPT level. Though we did not further elucidate the cause, there are reports indicating the benefit of exercise on liver fat reduction [15].

Recent opinion from Sports Medicine highlights the potential health benefits of standing and light-intensity activities [16]. In our study, we found the intensity of females' exercise tends to be lighter than males'. It is possible that their intensity and volume need to be increased in order to achieve metabolic profiles, especially glycemic control.

In this study, in male diabetic patients with adequate exercise, they also had better lifestyle like less smoking, less alcohol drinking and more self-monitoring of glucose. These factors all contribute to better metabolic outcomes. Exercise seemed to be a marker of self-discipline in male but not in female. It is an interesting phenomenon that those who are older and with longer diabetes duration have more adequate leisure time physical activities. This might reflect their increased awareness of the importance of exercise on the management of diabetes or simply is due to the fact that they have more spare time to do that. Additionally, it might seem paradoxical at first glance that their hemoglobin HA1C is lower than those who are younger and 
with shorter duration of diabetes. Or this might suggest that it is never too late to start exercising. The benefits may even counter the adverse effect of age and diabetes duration.

Our study has some limitations. First this is a cross-sectional survey, not a prospective study, which carries its intrinsic limitation, i.e. it is hard to infer cause-effect relationship. Second, our physical activity was asked by questionnaire which includes leisure-time physical activity only. Underestimation of physical activity might be present in three groups, especially in sedentary group, who are much younger and are expected to more physically active during work. Within this group, they possibly might have more manual labor, which was not considered as leisure time physical activity. If this is true, the benefits of exercise is obscured rather than exaggerated with our analysis.

\section{Conclusions}

Our data showed that $53.7 \%$ patients with type 2 diabetic patients have LTPA, but only $24.7 \%$ have adequate LTPA. Overall, adequate exercise group was older and had longer diabetes duration than non adequate exercise group. Better metabolic indexes were seen in male adequate physical activity subjects, but not in female counter parts. They also had better lifestyle habits which were not present in female subjects. Exercise intensity and volume were higher in male subjects too. To increase metabolic benefits from low intensity LTPA, increase of exercise volume is possibly useful.

\section{References}

1. Bray GA, Jablonski KA, Fujimoto WY, Barrett-Connor E, Haffner S, Hanson RL, et al. Relation of central adiposity and body mass index to the development of diabetes in the Diabetes Prevention Program. Am J Clin Nutr. 2008; 87(5):1212-1218.

2. Venables MC, Jeukendrup AE. Physical inactivity and obesity: links with insulin resistance and type 2 diabetes mellitus. Diabetes Metab Res Rev. 2009; 25 Suppl 1:S18-23. doi: 10.1002/dmrr.983.

3. Pi-Sunyer X, Blackburn G, Brancati FL, Bray GA, Bright R, Clark JM, et al. Reduction in weight and cardiovascular disease risk factors in individuals with type 2 diabetes: one-year results of the look AHEAD trial. Diabetes Care. 2007; 30(6):1374-1383.

4. Standards of medical care in diabetes--2012. Diabetes Care. 2012; 35 Suppl 1:S11-63. doi: 10.2337/dc12-s011.

5. Sheu WH, Chang TM, Lee WJ, Ou HC, Wu CM, Tseng LN, et al, Effect of weight loss on proinflammatory state of mononuclear cells in obese women. Obesity (Silver Spring). 2008; 16(5):1033-1038. doi: 10.1038/oby.2008.37.
6. Colberg SR, Sigal RJ, Fernhall B, Regensteiner JG, Blissmer BJ, Rubin $\mathrm{RR}$, et al. Exercise and type 2 diabetes: the American College of Sports Medicine and the American Diabetes Association: joint position statement executive summary. Diabetes Care. 2010;33(12):26922696. doi: $10.2337 /$ dc10-1548.

7. Golubic R, Martin KR, Ekelund U, Hardy R, Kuh D, Wareham N, et al. Levels of physical activity among a nationally representative sample of people in early old age: results of objective and selfreported assessments. Int J Behav Nutr Phys Act. 2014; 11:58. doi: 10.1186/1479-5868-11-58.

8. Perreault L, Ma Y, Dagogo-Jack S, Horton E, Marrero D, Crandall J, et al. Sex differences in diabetes risk and the effect of intensive lifestyle modification in the diabetes prevention program. Diabetes Care. 2008;31(7):1416-1421. doi: 10.2337/dc07-2390.

9. Collier SR. Sex differences in the effects of aerobic and anaerobic exercise on blood pressure and arterial stiffness. Gend Med. 2008; 5(2):115-123. doi: 10.1016/j.genm.2008.06.002.

10. Boulé NG, Haddad E, Kenny GP, Wells GA, Sigal RJ. Effects of exercise on glycemic control and body mass in type 2 diabetes mellitus: a metaanalysis of controlled clinical trials. JAMA. 2001; 286(10):1218-1227.

11. Nielsen PJ, Hafdahl AR, Conn VS, Lemaster JW, Brown SA. Metaanalysis of the effect of exercise interventions on fitness outcomes among adults with type 1 and type 2 diabetes. Diabetes Res Clin Pract. 2006; 74(2):111-120.

12. Umpierre D, Ribeiro PA, Schaan BD, Ribeiro JP. Volume of supervised exercise training impacts glycemic control in patients with type 2 diabetes: A systemic review with meta-regression analysis. Diabetologia. 2013; 56(2):242-251. doi: 10.1007/s00125-0122774-z.

13. Balducci S, Zanuso S, Cardelli P, Salvi L, Bazuro A, Pugliese L, et al. Effect of high- versus low-intensity supervised aerobic and resistance training on modifiable cardiovascular risk factors in type 2 diabetes; the Italian Diabetes and Exercise Study (IDES). PLoS One. 2012; 7(11):e49297. doi: 10.1371/journal.pone.0049297.

14. Marwick TH, Hordern MD, Miller T, Chyun DA, Bertoni AG, Blumenthal RS, et al. Exercise training for type 2 diabetes mellitus: impact on cardiovascular risk: a scientific statement from the American Heart Association. Circulation. 2009; 119(25):3244-3262. doi: 10.1161/ CIRCULATIONAHA.109.192521.

15. Johnson NA, Keating SE, George J. Exercise and the liver: implications for therapy in fatty liver disorders. Semin Liver Dis. 2012; 32(1):6579. doi: 10.1055/s-0032-1306427.

16. Smith L, Ekelund U, Hamer M. The potential yield of non-exercise physical activity energy expenditure in public health. Sports Med. 2015; 45(4):449-452. 